\title{
WHY ARE DISCOUNTED PRICES PRESENTED WITH FULL PRICES? THE ROLE OF EXTERNAL PRICE INFORMATION ON CONSUMERS' LIKELIHOOD TO PURCHASE
}

\begin{abstract}
Apart from being a cost, prices inform consumers on the quality of goods. To retain informative power, discounted prices are often presented together with their original value as an External Reference Price (ERP). Observing the impact of the ERP on consumer preferences using two contingent valuation surveys to wine consumers, the paper observes that the presence of both prices and ERPs guide consumer choices. In particular, ERPs shift the attention of consumers towards expensive products and high discounts, by providing information on quality and allowing for time-efficient decisions. Results show that ERPs: a) have a positive impact on preferences, but less (in absolute value) than prices; b) stimulate the choice of items with high price and large discounts; c) make consumers revise their choices. The presence of an ERP can, in certain conditions, lead to a positive response to high prices.
\end{abstract}

Keywords: external reference price; price-quality proxy; discounts; contingent valuation; bivariate ordered probit.

JEL code: C010; D030; D120; L810; M310.

Word count: 6,580;

Pages: 20. 


\section{INTRODUCTION}

In modern markets consumers are often called to choose in conditions of risk and uncertainty about the intrinsic quality of goods they buy (Ariely and Norton, 2011; Akerlof, 1970). However, buyers can use prices to determine the quality of goods and to rank different options by quality before a choice (Monroe, 1973; Rao and Monroe, 1989; Kirmani and Rao, 2000; Rao, 2005; Gerstner, 1985), assuming a positive price-quality correlation (Ding et al., 2010). This price-quality heuristic is based on the common knowledge that high quality requires expensive inputs and can be produced in limited quantity (Bagwell and Riordan, 1991). Furthermore, suppliers of high quality goods use high prices to signal their superior quality (Spence, 1973; Stiglitz, 1987; Spence, 2002) and can count on future profits only if the high price-high quality relation truly exists (Cooper and Ross, 1984; Milgrom and Roberts, 1986; Bagwell and Riordan, 1991).

While research has explored extensively this price-quality proxy, there is little understanding of the cognitive distortion discounts may cause to the assumption of a positive price-quality correlation (Palazon and Delgado-Ballester, 2009). For example, in the occurrence of a temporary price change, a product worth $£ 15$ and sold at $£ 10$ would be perceived to perform less well at the discounted price compared to its full price if the latter is unknown. Any imperfect expectation should correct itself through repeated consumption, but quality distortions caused by price perception are not fully conscious (Plassman et al., 2008; Shiv et al., 2005a): they alter the experience performance of goods, limiting an effective learning process.

A common strategy to overcome this problem is to provide quality cues. Retailers often provide consumers with External Reference Prices (ERP) (Kalyanaram and Winer, 1995; Mazumdar et al., 2005). This piece of information refers to: the price of a direct substitute, referred to as a contextual reference price (Rajendran and Tellis, 1994), i.e. the price of a competing brand; or an advertised reference price, i.e. the price of the same good in a different location (e.g. a competing store), in a previous shopping trip (a temporal reference price), or from a different source 
(e.g. the recommended retail price) (Mazumdar et al., 2005). ERPs are called external because they are not generated within the consumer's mind and represent pieces of information external to the bundle of attributes that are needed in a transaction (Zeithaml, 1988; Mayhew and Winer, 1992; and Kopalle and Lindsey-Mullikin, 2003).

The primary objective of this article is to understand consumer behaviour in the presence of an ERP. The literature on the subject is well established (e.g. Mayhew and Winer, 1992; and Kopalle and Lindsey-Mullikin, 2003), but the mechanisms underlying their use are not yet fully understood. Current research indicates that consumers' response to prices contains a significant behavioural component driven by a subjective cognitive interpretation of ERPs, as well as feelings and emotions ERPs may evoke (Thomas, 2013; Cheng and Monroe, 2013). Importantly, ERPs might induce an automatic consumer response, i.e. a positive prime, which makes choices faster by reducing cognitive effort. Nevertheless, it remains unclear whether ERPs direct and change consumer choices. To explore this matter, this article estimates a utility function for wine, a good with high search costs, to understand whether choices with knowledge of an ERP differ from those without it. Using the same dataset, Panzone (2012) observes that exogenous changes in ERP alter the perceived quality of goods, but does not compare choices with and without ERPs.

Specifically, ERPs could cause an anchoring bias (Tversky and Kahneman, 1974, Ariely et al., 2003), whereby consumers base their quality expectations on ERPs possibly perceiving them as more reliable than their own inference (see also Kopalle et al., 2012). Similarly, ERPs could cause an attentional bias (Smith et al., 2006): by signalling quality, they may make other pieces of information less relevant to the choice task. Adaptation theory indicates that expectations over future outcomes depend on past experienced outcomes and current stimuli (Chen, 2009), and because past hedonic performances unconsciously depend on ERPs (Plassmann et al., 2008; Shiv et al., 2005a) their presence is likely to reinforce a bias and make it automatic. The result of this inferential process may lead consumers to prefer an item when both expensive (i.e. high ERP) and with a high discount (i.e. low price to pay), giving little attention to other product characteristics. 
Choices rely heavily on non-sensory information (Peri, 2006; Jaeger, 2006) such as contextual cues and marketing activities (Dawson, 2013; Dhar and Novemsky, 2008), which are crucial in some wine segments (Lockshin et al., 2006). ERPs anchor a consumer's valuation to the extent that any price information is assessed with respect to its original price. Economic theories of consumer behaviour allow for an impact of ERPs on choices, but their presence would not be anticipated to affect price sensitivity, because price alone determines the allocation of money. Note that the ERP should be expected to restore the distortion of the price-quality proxy in the presence of discounts with an overall neutral effect, and a high impact of ERPs on utility would entail consumers can be "nudged" into purchasing a good just by including an ERP.

A second objective is to understand how ERPs are used. Consumers use price to infer unobservable product quality (e.g. Monroe, 1973; Kirmani and Rao, 2000; Rao, 2005). However, prices may become (partially or fully) uninformative when an ERP is present, because quality is now communicated by another source. Furthermore, consumers gain positive feelings from the knowledge of a discount, and the ERPs make this monetary reward salient (Mayhew and Winer, 1992; Kopalle and Lindsey-Mullikin, 2003). Knowledge of the discount then reduces the importance of the cost component of price, reducing price sensitivity. A final objective is to observe whether the presence of ERPs changes consumer choices. By comparing consumers' responses in the two CV surveys, it is possible to examine whether the same respondent revises her choice when the ERP is known. Data indicate $36 \%$ of consumers changed their initial decision, and inconsistency is a frequent outcome. Consumers revised their utility downwards more frequently than upwards, depending on the position of price relative to the ERP.

These research questions are explored through two contingent valuation (CV) surveys to wine consumers. Albeit rarely used for market goods (e.g. Park and MacLachlan, 2008), this technique is recognised as reliable in the determination of consumer preferences (Hanemann, 1994; Wong, 1997; Carson et al., 2001; Alberini et al., 2003). The use of stated preferences allows estimating a utility function for wine removing the collinearity between price and ERP, and the possible 
endogeneity of discounts. In the first CV survey, respondents indicated their intention to purchase an existing wine at a given randomly allocated price. In the second survey, respondents repeated the task in the presence of an advertised ERP. Because CV responses are not fully incentive-compatible (Wertenbroch and Skiera, 2002), results are compared to estimates from revealed preference.

The remainder of the paper is as follows. Section 2 introduces the econometric model used in the empirical analysis. Section 3 presents the data collection process. The case study focuses on the wine market because of its highly differentiated supply, and common use of price as quality proxy (Mitchell and Greatorex, 1989; Chaney, 2000; Drummond and Rule, 2005; Ritchie, 2007). Furthermore, wine choices appear to be made in condition of risk and uncertainty over intrinsic quality (Mitchell and Greatorex, 1989; Drummond and Rule, 2005), making the context suitable for the purposes of this study. Results are presented in section 4, while section 5 discusses the findings of the article and concludes.

\section{ECONOMETRIC MODEL}

The present section incorporates the ERP into a simple economic model of choice. In the market, a consumer $j$ with income $Y_{j}$ is expected to purchase a wine $i$ with characteristics $X_{i}$ sold at a market price $P_{i}$ only if he expects a positive utility from the intrinsic quality of the good, $S_{i}$. The utility of the consumer corresponds to

$$
U_{i j}=U\left(S_{i}\right)
$$

$S_{i}$ is unknown to consumers, and choices are risky and lead to uncertain outcomes, particularly in information intensive markets. Consumers will then infer $S_{i}$ on the basis of information available.

\subsection{Only price available}

In the absence of an objective measure of $S_{i}$, consumers estimate quality on the basis of observable characteristics (Broniarczyk and Alba, 1994) and price (Rao, 2005), through a subjective process (Alba and Hutchinson, 2000). The estimated $S_{i j}$ can be specified as 


$$
\hat{S}_{i j}=g\left(X_{i}, P_{i}, D_{j}\right)
$$

where $D_{j}$ are demographics. The resulting utility function can then be written as

$$
U_{i j}=\beta_{o}+\beta_{1} \cdot X_{i}+\beta_{2} \cdot D_{j}+\beta_{3} \cdot P_{i}+\beta_{4} \cdot Y_{j}+\eta_{i j}
$$

where $\eta_{i j}$ are normally distributed residuals. The coefficient of price $\left(\beta_{3}\right)$ in equation (3a) refers to the utility of price as a cost, $\delta_{C}$, and as information about product quality, $\delta_{I}$, so that $\beta_{3}=\left(\delta_{I}+\delta_{C}\right)$. A negative $\beta_{3}$ indicates that the absolute value of the cost element is larger than the informational one. Conversely, the price coefficient is positive whenever price as information is more important than price as a cost (Veblen, 1899; Leibenstein, 1950; Basmann et al., 1988). Finally, the equality $\left|\delta_{C}\right|=\left|\delta_{I}\right|$ implies $\beta_{3}=0$, a condition that can be misinterpreted with price non-attendance (Scarpa et al., 2009).

\subsection{Price and ERP available}

Imagine now consumer $j$ is presented with an ERP. This information indicates the actual valuation of the product before the discount, and can be used in the inferential process (Urbany et al., 1988; Mayhew and Winer, 1992). The quality-inference function becomes

$$
\hat{S}_{i j}=g\left(X_{i}, P_{i}, D_{j}, E R P_{i}\right)
$$

which leads to the utility function

$$
U_{i j}=\alpha_{o}+\alpha_{1} \cdot X_{i}+\alpha_{2} \cdot D_{j}+\alpha_{3} \cdot P_{i}+\alpha_{4} \cdot E R P_{i}+\alpha_{5} \cdot Y_{j}+\varepsilon_{i j}
$$

Expectedly, the inclusion of a further attribute impacts choices (Islam et al., 2007) because it reshapes the perception about the relative price and quality of the product (a content aspect). The ERP might also change the difficulty of making a decision (a process aspect), a feature the proposed models captures only under the assumption that the former is mediated by the latter, i.e. the change in difficulty is only caused by the different inferential process when ERPs are provided ${ }^{1}$.

\footnotetext{
${ }^{1} \mathrm{I}$ am indebted to an anonymous referee for highlighting this point.
} 
The literature provides no understanding of whether market price and ERP substitute or complement each other in the provision of quality information. In other words, it is unclear whether consumers stop using market price as a quality cue when an ERP is available. Consequently, the price coefficient $\alpha_{3}$ might retain both cost and some quality information, so that $\alpha_{3}=\left(\delta_{C}+\delta_{I}^{P}\right)$; while the coefficient of the ERP, $\alpha_{4}=\delta_{I}^{E R P}$, contains information on quality measured as the monetary size of the savings (Mayhew and Winer, 1992; Kopalle and Lindsey-Mullikin, 2003). The ERP is expected to contribute positively towards utility $\left(\alpha_{4}>0\right)$.

\subsection{The utility of price in the presence of discounts}

To observe the influence of discounts on utility, the paper exploits the relation between price and ERP. In particular, retailers choose price as $P_{i}=\left(1-\pi_{i}\right) \times E R P_{i}$, where $\pi$ is the rate of discount. Substituting this relation into equation (3b) leads to

$$
U_{i j}=\alpha_{o}+\alpha_{1} \cdot X_{i}+\alpha_{2} \cdot D_{j}+\left[\alpha_{3} \cdot\left(1-\pi_{i}\right)+\alpha_{4}\right] \cdot E R P_{i}+\alpha_{5} \cdot Y_{j}+\varepsilon_{i j}
$$

In the absence of a discount $(\pi=0)$, equation (4) converges to equation (1). If consumers do not use ERPs $\left(\alpha_{4}=0\right)$ and prices convey no information $\left(\delta_{I}^{P}=0\right)$, the estimated price coefficient only reflects a response to changes in cost to the consumer (i.e. a pure Hicksian price effect). In equation (4), a discount changes the sensitivity to the full price of a product: because $\left(1-\pi_{i}\right) \geq 0$, an increase in $\pi$ reduces the disutility of the cost component of price $\left(\alpha_{3}<0\right)$, but not that of the ERP $\left(\alpha_{4}>0\right)$. The effect of price on choice is positive for sufficiently high discounts, precisely whenever $\left[-\alpha_{3} \cdot(1-\pi)\right]<\alpha_{4}$.

\subsection{Estimation of the utility function}

To estimate equations (3a) and (3b) empirically, utility is treated as a latent construct $U_{i j}^{*}$, whose relation with $U_{i j}$ is defined as 


$$
\begin{aligned}
& U_{i j}=1 \text { if } \quad 0<U_{i j}^{*}<+\infty \\
& U_{i j}=0 \text { if } \quad-\infty<U_{i j}^{*} \leq 0
\end{aligned}
$$

The approach in equation (5) is typical of any binary choice model, for both revealed and stated preferences (e.g. Lockshin et al., 2006). An estimation of the relation between ERP and price within the same utility function using revealed preferences is affected by multicollinearity problems: the discounted price is a function of the original price of the product; and price is collinear with product characteristics. At the same time, retailers decide price promotions based on the expected response of consumer segments (Kopalle et al., 1999), making discounts endogenous.

Consequently, a stated preference approach is more appropriate for the objective of this research, and the empirical analysis uses a Double Bounded Dichotomous Choice (DBDC) CV survey that randomly allocates bid values independent on ERP and wine characteristics. The same utility function could have been estimated using a choice experiment (e.g. Mueller et al., 2010; Lockshin et al., 2006), allowing respondents to compare different alternative products in the market and allowing for more realistic substitution patterns. However, a CV methodology was preferred for its flexible implementation and the simplicity of the task in the absence of an interviewer. Moreover, the objective was to allow consumers valuing items in isolation to avoid a "Distinction bias" (Hsee and Zhang, 2004), whereby the presence of other products leads to a biased perception of differences between them. In a complex context as the wine market, the bias would overestimate the role of the ERP (i.e. large response to ERP when products are similar). Results indicate that estimates for price and ERP from revealed preferences are comparable to those of the CV.

The econometric approach used merges two branches of CV research: it integrates the simultaneous estimation of the two rounds of bidding (Cameron and Quiggin, 1994) with a utility scale incorporating uncertainty (Wang, 1997). Specifically, the CV uses a 5-point utility scale (Welsh and Poe, 1998; Alberini et al., 2003) with uncertainty points, "Unsure" and "Probably" options (Wang, 1997; Welsh and Poe, 1998; Alberini et al., 2003), which allow consumers to locate 
their preferences more accurately and reduce the hypothetical bias. The relation between $U_{i j}^{*}$ and $U_{i j}$ becomes

$$
\begin{array}{ccc}
U_{i j}=4=\text { Yes } & \text { if } & \mu_{3}<U_{i j}^{*}<+\infty \\
U_{i j}=3=\text { ProbablyYes } & \text { if } & \mu_{2}<U_{i j}^{*} \leq \mu_{3} \\
U_{i j}=2=\text { Unsure } & \text { if } & \mu_{1}<U_{i j}^{*} \leq \mu_{2} \\
U_{i j}=1=\text { Probably No } & \text { if } & \mu_{0}<U_{i j}^{*} \leq \mu_{1} \\
U_{i j}=0=N o & \text { if } & -\infty<U_{i j}^{*} \leq \mu_{0}
\end{array}
$$

where $\mu$ indicates the average cut-off points of the utility scale.

DBDC CV surveys ask consumers to state their preferences in two subsequent rounds, differing only in the value of the random bid $P$. Each round gives indications on the underlying utility function of consumers, and can be analysed by a two-equation system of simultaneous regressions

$$
\begin{aligned}
& U_{1 i j}^{*}=\beta_{1, o}+\beta_{1,1} \cdot X_{i}+\beta_{1,2} \cdot D_{j}+\beta_{1,3} \cdot P_{1 i}+\beta_{1,4} \cdot Y_{j}+\eta_{1 i j} \\
& U_{2 i j}^{*}=\beta_{2, o}+\beta_{2,1} \cdot X_{i}+\beta_{2,2} \cdot D_{j}+\beta_{2,3} \cdot P_{2 i}+\beta_{2,4} \cdot Y_{j}+\eta_{2 i j}
\end{aligned}
$$

and

$$
\begin{aligned}
& U_{1 i j}^{*}=\alpha_{1 o}+\alpha_{1,1} \cdot X_{i}+\alpha_{1,2} \cdot D_{j}+\alpha_{1,3} \cdot P_{1 i}+\alpha_{1,4} \cdot E R P_{i}+\alpha_{1,5} \cdot Y_{j}+\varepsilon_{1 i j} \\
& U_{2 i j}^{*}=\alpha_{2, o}+\alpha_{2,1} \cdot X_{i}+\alpha_{2,2} \cdot D_{j}+\alpha_{2,3} \cdot P_{2 i}+\alpha_{2,4} \cdot E R P_{i}+\alpha_{2,5} \cdot Y_{j}+\varepsilon_{2 i j}
\end{aligned}
$$

Residuals of both equations are assumed normally distributed and correlated, with a polychoric correlation coefficient $\rho$ (Greene and Hensher, 2009, page 225). Parameters are estimated using a bivariate ordered probit regression.

To further limit the occurrence of a hypothetical bias in this CV exercise, the survey uses a cheap-talk script (Lusk, 2003; Cummings and Taylor, 1999). This step entails the presentation of a text containing clear instructions on the economic implications of the answers to respondents (Lusk, 2003). These two steps have demonstrated effectiveness in moderating the hypothetical bias to a great extent. The questionnaire also followed peer-reviewed guidelines to minimise the potential impact of biases in CV surveys (i.e. Venkatachalam, 2004; Carson, 2000; Carson et al., 2001). To 
assess the robustness of the results, estimated coefficients from stated preferences are compared with revealed preferences from a nested logit regression in the same study area from Panzone (2012). Because of the nature of the models, revealed preferences estimate segment choice parameters, while the $\mathrm{CV}$ task estimates brand choice parameters.

\section{THE SURVEY}

Preferences for wine have been collected though a DBDC CV survey in the Greater Reading postcode area (Berkshire, United Kingdom). Respondent were adults resident in the area and randomly selected from the edited version of the electoral register ${ }^{2}$. Interviewees were presented with an existing wine sold in the area ( $750 \mathrm{ml}$ bottle), and asked whether they would be willing to purchase it at a randomly allocated price. The sample of wines was identified through an in-store survey in off-licence retailers in the study area (see table 1). The survey registered the purchase of 260 wines purchased by 160 consumers. Information collected included product characteristics (on the label), original and discounted price of the product (verified in store and on the receipt), and the characteristics of the consumer (details can be found in Panzone, 2012). The objective of this first survey was to obtain a representative sample of both wines and respondents, and any product was included as many times as it appeared (only 5 items were repeated twice). Participants received no incentive for participation in any of the surveys.

Each wine in the sample was randomly allocated to a different resident, with no specific information on the purpose of the study. Respondents were presented with a replica label containing all the information on the real bottle of the wine (figure 1), and asked whether they would be willing to buy it at a price; respondents were then asked their purchase intention at a second bid, higher in case of positive response or lower to negative responses. Bid values were prepared in four different formats following Rowe et al. (1996) (table 2) and planned to fit the range of selling prices obtained from a pilot survey (32 wines, range $£ 2.68-£ 8.99$ ). Bids have been approximated to their

\footnotetext{
${ }^{2}$ http://www.ico.org.uk/for_the_public/topic_specific_guides/electoral_register
} 
closest 9 ending (Schindler and Kibarian, 1996; Schindler and Kirby, 1997), consistent with revealed preference data $(66.0 \%$ of the prices and $74.7 \%$ of ERPs ending in 9$)$.

After this first step, respondents repeated the choice task with a "was-now" advertised ERP (Rajendran and Tellis, 1994). Here, a sentence read "TWO MONTHS AGO, this wine was actually sold in [Name of the retailer where the wine was surveyed] at a price of $£$ [Full price of the wine at the time of the in-store survey]". Bid values for the two rounds were identical to those in the first step, and the choice probability task was identical (a within-subject treatment). No information was provided regarding the price change, and the difference between the ERP and the bid could be perceived as either a discount or an exogenous price change. Precisely, the ERP was larger for 123 respondents, lower for 64 respondents, and identical for 7 , an unusual feature for the marketplace that retains the idea of a quality proxy.

To maximise the response rate, the 260 questionnaires (each containing one of the wines collected in the mall survey) were sent out in four versions to four potential respondents, each containing one of the four scales in table 2. Only the first response to arrive was included in the final analysis. Of the 1,040 questionnaires sent (260 wines x 4 versions, 226 of which returned valid and complete), the final sample covered 194 of the 260 initial wines. The respondents of the 32 excluded questionnaires did not differ significantly on most demographics, although respondents in the final sample tend to: spend more on wine; buy more wine; belong to households with more wine drinkers; be men (10\% significance level); more frequently be $18-25$ years old $(10 \%)$ and less frequently be 46-55 years old; have graduate education; and less frequently report an income $<£ 15,000$ whilst more frequently indicating income band $>£ 55,000^{3}$.

\section{RESULTS}

Before proceeding to the results, it worth observing whether the price behaviour of the data collected is comparable with observed market data (figure 2 and table 3). An initial analysis

\footnotetext{
${ }^{3}$ I am grateful to an anonymous referee to suggest the inclusion of this information.
} 
suggests that the sample of wine proposed in the CV survey fits within the price range used by respondents. The average self-reported usual price paid for a wine is $£ 5.41$ (range: $£ 3.00-£ 15.00$ ), very close to the average of the second bid presented (£5.44). At the same time, wines in the sample are more expensive than usually paid if considered before discount (£6.79) but cheaper at their market price (£5.17). As a comparison, data from Tesco indicate that the average price paid in their local stores during the survey (April-May 2009) was in the range $£ 4.30-£ 4.11$ in supermarkets and $£ 4.46-£ 4.44$ in convenience stores (figure 3 ), with full prices between $£ 4.5$ and $£ 5$. Consequently, wines included in the sample fit the price segment of interest to respondents. At the same time, consumers in the mall intercept did not differ significantly from those of the CV survey, the only difference being the presence of non-resident population (e.g. students) in the mall intercept.

The impact of price and ERP on consumers' utility has been estimated in accordance with the specifications of equations (3a) and (3b). Product characteristics included in the regression are colour, AOC, alcohol content, retailer's label, and age of the wine ${ }^{4}$. Characteristics of the respondent include the logarithm of income and age ${ }^{5}$, the number of wine drinkers in the household, and self-reported wine expertise (on a 5-point scale). Variables are summarised in table 4. The dependent variable is the answer to each bid of the $\mathrm{CV}$ exercise.

\subsection{Did consumers use the ERP in stating their preferences?}

Estimated coefficients of equations (3a) and (3b) are presented in table 5. Models A, C, and E estimate utility when ERPs are unavailable, while models B, D, and F when ERPs are known. The last column in table 5 refers to revealed preferences. Models differ on the covariates included: product characteristics correlate with the ERP, and utility could be endogenous in wine expertise. As a result, models A and B only include price variables and demographics; models C and D add product characteristics; while model E and F include wine knowledge. Revealed preferences only

\footnotetext{
${ }^{4}$ Age for wines reporting no vintage year was replaced by the mean value of the sample and identified through a dummy variable.

${ }^{5}$ Income (in 1,000 pounds) and age were included as the median of the income band selected by the respondent. Missing income information was replaced by the mean value and identified through a dummy variable.
} 
include product characteristics to ensure convergence given the relatively low number of observations. Importantly, the coefficients of price are considerably close across specifications, an indication of robustness. The coefficient of the ERP appears larger in real transactions, although part of this difference is caused the high correlation between ERP and price $(0.90, \mathrm{p}<0.01)$.

As expected, the bid has a negative impact on stated choice, while the ERP is positive and significant. Figure 4 shows graphically the relation between price and ERP and utility using estimates from the second round of models A-B: the coefficient of the bid in model A sits between the coefficients of bid and ERP in model $\mathrm{B}$, an indication that price sensitivity mildly declines when the ERP is present. In absolute value, the ERP has a lower impact on choice than the bid, with a ratio of $0.41-0.63$ ( 1 for revealed preferences). This value corresponds to a consumer's willingness to pay for a unit of ERP, i.e. $\left|\frac{\partial U / \partial E R P}{\partial U / \partial B i d}\right|=\left|\frac{\partial B i d}{\partial E R P}\right|$ : consumers value a unit increase in ERP around $£ 0.41-0.63$, an indication of its value as an instrument to reduce the cognitive task.

A series of Wald tests observe the relation between bid and ERP (table 6). First, coefficients of both bid and ERP do not change significantly across bidding rounds. Also, the estimated impact of bids does not vary across models $\left(\alpha_{3}=\beta_{3}\right.$ ), implying that the total impact of price plus ERP on choice is larger than that of price alone $\left(\alpha_{3}+\alpha_{4}>\beta_{3}\right)$. Finally, the ERP is as important as the bid in the first round of bidding, but becomes significantly less important than the bid in the second round $\left(\alpha_{3}+\alpha_{4}<0\right)$. These results indicate that ERPs adds significant information to consumers, but without reducing the importance of price. Consequently, the ERP does not seem to remove the informational content of price, but rather integrates it. The low number of observations could be responsible for these conservative results.

Observing all other variables, the likelihood to purchase depends only on alcohol content, colour, and missing vintage year. The presence of the ERP might cause an informational bias (Smith et al., 2006): consumers stop using information on alcohol content and missing year in the 
second $\mathrm{CV}$, limiting their attention to the colour of the wine. Changes in the coefficient of specific attributes are consistent with the interference of ERPs on hedonic taste perception (Plassmann et al., 2008), but could be partly due to collinearity between ERP and product characteristics. Coefficients of product attributes differ substantially in size and sign between revealed and stated preference, with alcohol being the only coefficient comparable in magnitude and sign across preference type. The different structure imposed by each model plays a major role in the different results. Apart from age and income, demographics contribute modestly to the model, while a significant $\rho$ indicates unobservable tastes contained in the residuals have an important role.

To add consistency with existing research on reference pricing (Kalyanaram and Winer, 1995; Kopalle and Lindsey-Mullikin, 2003; Kumar et al., 1998; Mayhew and Winer, 1992; Mazumdar et al., 2005), the same model is estimated as asymmetric reference price model (Mazumdar and Papatla, 2000; Rajendran and Tellis, 1994; Mazumdar et al., 2005) to allow for a different response to ERP depending on whether it is larger or smaller than price. This model incorporates an Internal Reference Value (IRV) equal to the fitted utility from the first CV survey (models A, C, E). In fact, respondents could determine whether to make a purchase on the basis of their own inference (Lowe and Alpert, 2010), and the IRV could be the real driver of the previous results. To this end, the estimated equation is

$$
U_{i j}=\phi_{o}+\phi_{1} \cdot P_{i}+\phi_{2} \cdot I R V_{i j}+\phi_{3} \cdot H_{j} \cdot\left(E R P_{i}-\operatorname{Bid}_{i}\right)+\phi_{4} \cdot L_{j} \cdot\left(E R P_{i}-B_{i d}\right)+u_{i j}
$$

where $H$ and $L$ are functions equal to one only if the ERP is higher $(H)$ or lower $(L)$ than price.

Results (table 7) confirm that ERPs influence choice probability primarily when larger than price, while IRVs tend to have a negative impact on choice when the ERP is known (the coefficient is not significant in the first round). As expected, the bid retains a significantly negative coefficient, and results appear robust to variable specification. The negative influence of IRV when ERPs are available is consistent with Plassmann et al. (2008): consumers give high scores to a low-price wine 
when price is unknown, and to a high-price wine when price is known, expecting a hedonic performance increasing with price.

\subsection{Does the ERP complement or substitute quality information provided by price?}

Results from table 5 indicate that consumers use both price and ERP in their choices. This section explores whether price retains its role as quality proxy once the ERP is available. The same question can be asked as whether price and ERPs complement or substitute each other in the provision of information on product quality. A Wald test presented in table 6 failed to reject the null hypothesis that the informational component of price remains the same when the ERP is known, so that $\left(\delta_{C}+\delta_{I}\right)=\left(\delta_{C}+\delta_{I}^{P}\right)$. This point is supported by a similar coefficient of price in the presence or absence of ERPs (table 5). Wald tests also determine that the ERP adds explanatory power to the model, $\left(\delta_{C}+\delta_{I}^{P}\right)+\left(\delta_{I}^{E R P}\right)>\left(\delta_{C}+\delta_{I}\right)$, and the overall impact of bid and ERP is negative, $\left(\delta_{C}+\delta_{I}^{P}\right)+\left(\delta_{I}^{E R P}\right)<0$. These results imply that ERPs contribute with new information, i.e. $\left(\delta_{I}^{E R P}\right)>0$, but consumers keep using price to infer information on quality. In other words, price does not seem to lose its role as quality proxy, and the ERP complements it. A formal identification of each $\delta$ requires an experimental setting and cannot be done using the present dataset.

\subsection{What is the impact of the rate of discount on utility?}

Besides communicating information, the ERP informs on the discount rate $\pi$, which can impact price sensitivity. As mentioned above, market price is a fraction of the original price: $\operatorname{Bid}_{i}=\left(1-\pi_{i}\right) \times E R P_{i}$, where $0 \leq \pi_{i} \leq 1$. Using the coefficients of the second bidding round of model B (table 5, similar results are obtained from all other models), utility can be written as

$$
U_{i}=0.1679 \times E R P_{i}-0.2883 \times \text { Bid }_{i}=0.1679 \times E R P_{i}-0.2883 \times\left[\left(1-\pi_{i}\right) \times E R P_{i}\right]
$$

which reduces to

$$
U_{i}=\left[-0.1204+\left(0.2883 \times \pi_{i}\right)\right] \times E R P_{i}
$$


Equation (9) indicates that purchase probability is negatively related to price $(-0.1204)$ in the absence of a discount $\left(\pi_{i}=0\right)$. This probability starts rising as discounts grow, reaching positive values for discounts larger than $41.76 \%$ (figure 5). The positive contribution of discounts is caused by a decline in sensitivity to the cost component of price (as in equation (4)): money spent becomes relatively less important when the ERP is available. This result also suggests that consumers might increase their attention to the potential money saved of price as discounts grow.

More generally, figure 5 shows that for sufficiently high discounts the probability of a purchase increases with the original price, particularly for expensive options with a large discount because $U\left(E R P_{i}, \pi_{i}\right)>0$, ceteris paribus. This result suggest that in an extreme scenario consumers could purchase an item generating negative utility in all other attributes, $U\left(X_{i}, D_{j}\right)<0$, as long as total utility is positive, i.e. $U\left(E R P_{i}, \pi_{i}\right)+U\left(X_{i}, D_{j}\right)>0$. This finding indicates that ERPs could lead to suboptimal choices that consumers might fail to realise, i.e. the consumer might purchase something she dislikes just because it is discounted. This cognitive shortcut could conflict with policy instruments (alcohol taxes, see Panzone, 2012), or stimulate the purchase of unnecessary goods and increase waste. Indeed, high quality products tend to have high ERP (Bagwell and Riordan, 1991) so that $U\left(X_{i}, D_{j}\right)>0$ whenever $U\left(E R P_{i}, \pi_{i}\right)>0$, but future research should assess under which condition this relationship holds.

\subsection{Did consumers revise their choice when the ERP was available?}

The final step of this analysis explores how consumers used the information contained in the ERP. In particular, the data indicates that ERPs play a positive role in the probability of a purchase through several different channels. Firstly, ERPs could reduce uncertainty: in the second bidding round, 18 respondents (out of 194) reported to be "Unsure" when the ERP was unavailable (15 in the first bidding round), and only 9 when the ERP was supplied (both bidding rounds), with only 3 people reporting uncertainty in both surveys ( 2 in the first round). Similarly, consumers might use 
ERPs as anchor for their choices: decisions on whether to purchase an item or not might depend on the relative position of price. In fact, ERPs sets a reference point and prices lower than the ERP might seem reasonable even if the price is still higher than what the wine is really worth. Importantly, part of this decline in uncertainty might have been caused by a repeated-choice task, where consumers gained knowledge (e.g. Hoeffler and Ariely, 1999) or by a testing effect (e.g., Porath et al., 2010), rather than the presence of an $\mathrm{ERP}^{6}$.

Consequently, it appears possible that ERPs constitute a possible source of adaptive bias: ERPs may be used to make time-efficient choices, reducing the costs of cognitive errors rather than their number (Haselton and Buss, 2003; Kool et al., 2010). The correct determination of an adaptive bias hinges on the knowledge of the real utility the consumer obtains from a good, but it is impossible to establish which CV collected the "real" expected utility. On average, the stated utility in the two initial bidding rounds (which are strictly comparable) with and without knowledge of the ERP do not differ, going from 1.89 (without ERP) to 1.91 (with ERP) (p=0.90), and are strongly correlated $($ Pearson correlation $=0.75, \mathrm{p}<0.01)$. Nevertheless, 69 out of 194 respondents $(36 \%)$ revised their initial intention to purchase when the ERP was supplied, with 38 (55\%) moving upwards and 31 (45\%) downwards (figure 7).

The odds of the probability of revising up or down were estimated for those 69 respondents who revised their choices using the following logistic regressions:

$$
\begin{aligned}
& C U_{i j}=\lambda_{0}^{U}+\lambda_{1}^{U} \cdot K N_{i}+\lambda_{2}^{U} \cdot P R_{i j}+\lambda_{3}^{U} \cdot H_{j}+\lambda_{4}^{U} \cdot L_{j}+e_{i j} \\
& C D_{i j}=\lambda_{0}^{D}+\lambda_{1}^{D} \cdot K N_{i}+\lambda_{2}^{D} \cdot P R_{i j}+\lambda_{3}^{D} \cdot H_{j}+\lambda_{4}^{D} \cdot L_{j}+u_{i j}
\end{aligned}
$$

where $C U$ and $C D$ indicate a change up or down the utility scale, $K N$ is self-reported knowledge, $P R$ is the purchase rate, while $H$ and $L$ indicate whether the ERP is higher or lower than the bid, respectively. Odd ratios (table 8 ) indicate that the probability of a purchase increases significantly if ERP is larger than price, while the probability of rejecting the purchase increases significantly if the

\footnotetext{
${ }^{6} \mathrm{I}$ am indebted to an anonymous referee for suggesting this point.
} 
ERP is lower than price, in both cases of more than $600 \%$. Very infrequent is an increase in the likelihood of a purchase when ERP < bid or viceversa. Consequently, the presence of ERPs contributes to consumer choices by providing a reference against which price is evaluated.

\section{DISCUSSION AND CONCLUSIONS}

The objective of this work is to understand the impact of ERPs on consumer behaviour. In particular, the article explores whether and to what extent the presence of ERPs influences consumer choices. Compared to previous research (Kalyanaram and Winer, 1995; Kopalle and Lindsey-Mullikin, 2003; Kumar et al., 1998; Mayhew and Winer, 1992), the aim is to understand the informational and priming role of ERPs, and in this respect the paper is novel. This article uses a stated preference approach (opposite to the general use of revealed preferences) to remove the correlation between ERP and prices. Through a CV survey, consumers reported their intention to purchase the same wine at a random bid twice, once ignoring and once knowing the full price of the wine some time before the survey (a "Was-now" advertised ERP). The survey explored preferences for wine in the Greater Reading area (UK), using a representative sample of wines sold in supermarkets of the same study area. The small sample size and the narrow range of consumers in the survey from a geographical point of view substantially limit the generalisability of the findings of this article, but identify significant patterns of behaviour in a homogeneous market.

The overall picture drawn by the results section is an "ERP dominance": the presence of both ERP and price directs choices towards discounted expensive products. In fact, consumers: a) rely importantly on price and ERP in their choices; and b) anchor their expectations to the ERP by evaluating price relative to this information. As a result, ERPs lead consumers to buy primarily on full and discounted prices, paying less attention to other observable quality signals. In the extreme case where the utility for price and discounts is sufficiently high, consumers could even choose products with low or negative utility from other characteristics. This behaviour is indicative of adaptive reasoning: consumers aim at reducing the cognitive costs of errors rather than their number 
when faced with risky decisions (Kool et al., 2010; Hilbert, 2012). Consumers can then reduce search costs for information by relying on high ERPs, willingly accepting the probability of mistake (Haselton and Buss, 2003; Kool et al., 2010). These results are relevant also in the use of price instruments in public policy, as taxation interacts with ERPs (see Panzone, 2012).

Four sets of results provide a picture that contributes to the understanding of how consumers use ERPs in their choices. Firstly, ERPs positively influence the probability of a purchase. Consumers are nudged into preferring high ERPs because they generate expectations on the unobservable quality that is imperfectly available when price is alone. Importantly, the ERP anchors consumer preferences, leading consumers to evaluate the price to pay with respect to the full price of the same good. The impact of price remains the same when the ERP is present, but ERPs provide an incentive towards a purchase by reducing the weight given to price as a cost. Additionally, consumers seem to rely less on observable characteristics and unobservable preferences when ERPs are provided.

Second, ERPs nudge consumers towards the purchase of goods with high full price and low discounted price, possibly leading to optimistic expectations over unobservable quality. In fact, ERPs provide useful information regarding the quality of the marketed good that complements the internal valuation of consumers. This finding is consistent with existing reference price theory according to which acceptance of external price information is mediated by internal quality valuation (e.g. Mazumdar et al., 2005). The ERP also has an important role on the decision-making process because it induces consumers to revise their choice, particularly when the ERP is greater than price. This "ERP dominance" is very likely a strategy that aims at reducing the cognitive costs of choices in markets with high information loads, where ERP is used as a quality cue. The empirical fieldwork analysed the wine market (a relative luxury) in the mass retail sector (a commodity market), which is characterised by a large heterogeneity of supply. Results might be stronger in markets where prices have a strong informational component, such as luxury goods. 
Third, ERPs seem to complement rather than reduce the informational content of prices. This external stimulus has no significant impact on the coefficient of the bid: its value is not significantly different in the absence or presence of external price information. The surprising result is that in absence of ERPs consumers appear optimistic in their price-quality inference, where the quality component of price seems not to vary too much once the ERP is known. This result is consistent with theories of compensatory reasoning (Chernev and Hamilton, 2008): the existence of a good with undesirable features (such as price) can be justified only on the grounds of desirable unobservable quality. Consequently, consumers might use ERPs to confirm the earlier quality inference. At the same time, adaptation theory (Lee et al., 2008) indicates consumers may adapt by accepting the quality of existing options, viewing available options optimistically.

Finally, the ERP operates through a reduction in the relevance of price as a cost. As discounts increase, the relative importance of price as quality proxy increases, and the utility of price can become positive for high discounts. Hence, consumers can be nudged into a purchase by providing both full and discounted price. In an extreme case, consumers could purchase a good expecting negative utility from observable product characteristic and positive utility from price and discount. It is unclear whether consumers consciously prefer products that happen to be on discount and patiently wait for a lower price to purchase them; or subconsciously direct their attention to price rather than product characteristics in the presence of a discount. Answers to debriefing questions suggest consumers are often aware that knowledge of the ERP changed their answer. However, it is unclear whether all consumers are aware of this mechanism (Plassman et al., 2008, suggests otherwise) and if they estimate correctly the magnitude of the impact.

Before concluding, it is worth mentioning the caveats of the present work. The first important limitation is presenting two surveys consecutively within the same questionnaire. Apart from learning (e.g. Hoeffler and Ariely, 1999) and testing effects (e.g., Porath et al., 2010), respondents could have seen the ERP before answering the first task, leading to similar coefficients for the bid. Different estimates for other attributes suggest this problem was not fundamental. Equally, two 
surveys within the same questionnaire might induce consumers to reflect on their willingness to be consistent in their response, despite the questionnaire indicating that the second task was intended as a completely new purchase (as in Bateman et al., 2008). A consistency bias should underestimate the number of consumers revising choices, therefore providing a possible downward bias that reinforces the findings of this article. At the same time, the different coefficients for attributes in the two exercises suggest that consistency did not undermine the implications of this article.

A second caveat is methodological. The survey manipulated the presence of ERP in a withinsubject setting by always providing a choice task without an ERP first and then a choice task with an ERP (no filler task between them). Accordingly, part of the results might be a consequence of an ordering bias (Halvorsen, 1996) that would give an upward bias to the effects of the ERP. However, ordering bias tends to underestimate coefficients in the second task, partially compensating the bias from the design, and overestimate coefficients in the first task, possibly providing optimistic estimates when ERPs were not available. Furthermore, consumers react differently to different type of promotions (DelVecchio, 2005): this analysis only focuses on absolute monetary savings, and results might not be transferable to non-price promotions or different framing (e.g. percentages).

To conclude, results in this article provide useful insights on the ability of the ERP to facilitate choices. Further research should explore the generalisability of these results, as well as giving a better insight on the implications of the reliance on the ERP as a proxy of quality can have on consumers' choices, welfare, and information externalities. 


\section{BIBLIOGRAPHY}

Akerlof, G.A. (1970) The Market for "Lemons": Quality Uncertainty and the Market Mechanism. The Quarterly Journal of Economics, 84 (3): 488-500.

Alba, J.W.; Hutchinson, J. W. (2000) Knowledge Calibration: What Consumers Know and What They Think They Know. Journal of Consumer Research, 27 (2): 123-156.

Alberini, A.; Boyle, K.; Welsh M. (2003) Analysis of contingent valuation data with multiple bids and response options allowing respondents to express uncertainty. Journal of Environmental Economics and Management, 45 (1): 40-62.

Ariely, D.; Loewenstein, G.; Prelec, D. (2003) "Coherent Arbitrariness": Stable Demand Curves Without Stable Preferences. The Quarterly Journal of Economics, 118 (1): 73-106.

Ariely, D.; Norton, M.I. (2011) From thinking too little to thinking too much: a continuum of decision making. Wiley Interdisciplinary Reviews: Cognitive Science, 2 (1): 39-46.

Bagwell, K.; Riordan, M. H. (1991) High and Declining Prices Signal Product Quality. The American Economic Review, 81 (1): 224-239.

Bainbridge, J. (2009) The future looks rosé. Marketing, 19 January 2009: 26-27.

Basmann, R. L.; Molina, D. J.; Slottje, D. J. (1988) A Note on Measuring Veblen's Theory of Conspicuous Consumption. The Review of Economics and Statistics, 70 (3): 531-535.

Bateman, I.J.; Burgess, D.; Hutchinson, W. G.; Matthews, D.I. (2008) Learning design contingent valuation (LDCV): NOAA guidelines, preference learning and coherent arbitrariness. Journal of Environmental Economics and Management, 55, (2), 127-141.

Boggis, C.; Holter, G.; Atkin, T.; Clark, L. (2008) Wine report 2008. Off-licence News, retrieved on http://www.offlicencenews.co.uk/downloads/wine_report08.pdf

Broniarczyk, S.M.; Alba, J.W. (1994) The Role of Consumers' Intuitions in Inference Making. Journal of Consumer Research, 21 (3): 393-407. 
Cameron, T.A.; Quiggin, J. (1994) Estimation Using Contingent Valuation Data from a "Dichotomous Choice with Follow-Up" Questionnaire. Journal of Environmental Economics and Management, 27 (3): 218-234.

Carson, R. T. (2000) Contingent Valuation: A User's Guide. Environmental Science and Technology, 34 (8): 1413-1418.

Carson, R. T.; Flores, N. E.; Meade, N. F. (2001) Contingent Valuation: Controversies and Evidence. Environmental and Resource Economics, 19 (2): 173-210.

Chaney, I. M. (2000) External Search Effort for Wine. International Journal of Wine Marketing, 12 (2): 5-21.

Chen, C. Y. (2009) Who I am and how I think: The impact of self-construal on the roles of internal and external reference prices in price evaluations. Journal of Consumer Psychology, 19 (3): 416-426.

Cheng, L.L.; Monroe, K.B. (2013) An appraisal of behavioral price research (part 1): price as a physical stimulus. AMS Review, 1-27.

Chernev, A.; Hamilton, R. (2008) Compensatory Reasoning in Choice. In Arie Kruglanski \& Joseph Forgas (eds.) The Social Psychology of Consumer Behavior, Frontiers of Social Psychology. Taylor\&Francis Group, New York (NY).

Cooper, R.; Ross, T. W. (1984) Prices, Product Qualities and Asymmetric Information: The Competitive Case. The Review of Economic Studies, 51 (2): 197-207.

Cummings, R.G.; Taylor, L.O. (1999) Unbiased Value Estimates for Environmental Goods: Cheap Talk Design for the Contingent Valuation Method. The American Economic Review, 89 (3): 649-665

Dawson, J. (2013) Retailer activity in shaping food choice. Food Quality and Preference, 28 (1): 339-347.

DelVecchio, D. (2005) Deal-prone consumers' response to promotion: The effects of relative and absolute promotion value. Psychology and Marketing, 22 (5): 373-391. 
Dhar, R.; Novemsky, N. (2008) Beyond rationality: The content of preferences. Journal of Consumer Psychology, 18 (3): 175-178.

Ding, M.; Ross Jr, W.T.; Rao, V.R. (2010) Price as an Indicator of Quality: Implications for Utility and Demand Functions. Journal of Retailing, 86 (1): 69-84.

Drummond, G.; Rule, G. (2005) Consumer confusion in the UK wine industry. Journal of Wine Research, $16(1), 55-64$.

Greene, William H.; Hensher, David A. (2009) Modeling Ordered Choices. Available online at http://pages.stern.nyu.edu/ wgreene/DiscreteChoice/Readings/OrderedChoiceSurvey.pdf.

Halvorsen, Bente (1996) Ordering effects in contingent valuation surveys. Environmental and Resource Economics, 8 (4): 485-499.

Hanemann W. M. (1984) Welfare Evaluations in Contingent Valuation Experiments with Discrete Responses. American Journal of Agricultural Economics, 66 (3): 332-341.

Haselton, M.G.; Buss, D.M. (2003) Biases in Social Judgment: Design Flaws or Design Features? In Forgas, J.; Williams, K.; von Hippel B. (Eds.), Responding to the social world: Implicit and explicit processes in social judgments and decisions. New York, NY: Cambridge.

Hilbert, M. (2012) Toward a synthesis of cognitive biases: How noisy information processing can bias human decision making. Psychological Bulletin, 138 (2): 211-237.

Hoeffler, S.; Ariely, D. (1999) Constructing Stable Preferences: A Look Into Dimensions of Experience and Their Impact on Preference Stability. Journal of Consumer Psychology, 8 (2): 113-139.

Hsee, C.K.; Zhang, J. (2004) Distinction Bias: Misprediction and Mischoice Due to Joint Evaluation. Journal of Personality and Social Psychology, 86 (5): 680-695.

Islam, T.; Louviere, J.J.; Burke, P.F. (2007) Modeling the effects of including/excluding attributes in choice experiments on systematic and random components. International Journal of Research in Marketing, 24 (4): 289-300. 
Jaeger, S.R. (2006) Non-sensory factors in sensory science research. Food Quality and Preference, 17 (1-2): 132-144.

Kahneman, D.; Wakker, P.P.; Sarin, R. (1997) Back to Bentham? Explorations of Experienced Utility. The Quarterly Journal of Economics, 112 (2): 375-406.

Kalyanaram, G.; Winer, R.S. (1995) Empirical generalizations from reference price research. Marketing Science, 14 (3): G161-G169.

Kirmani, A.; Rao, A. R. (2000) No Pain, No Gain: A Critical Review of the Literature on Signaling Unobservable Product Quality. Journal of Marketing, 64 (2): 66-79.

Kool, W.; McGuire, J.T.; Rosen, Z.B.; Botvinick, Matthew M. (2010) Decision making and the avoidance of cognitive demand. Journal of Experimental Psychology: General, 139 (4): 665 682.

Kopalle, P. K.; Lindsey-Mullikin, J. (2003) The impact of external reference price on consumer price expectations. Journal of Retailing, 79 (4): 225-236.

Kopalle, P.K.; Kannan, P.K.; Boldt, L.B.; Arora, N. (2012) The impact of household level heterogeneity in reference price effects on optimal retailer pricing policies. Journal of Retailing, 88 (1): 102-114.

Kopalle, P.K.; Mela, C.F.; Marsh, L. (1999) The Dynamic Effect of Discounting on Sales: Empirical Analysis and Normative Pricing Implications. Marketing Science, 18 (3): 317-332.

Kumar, V.; Hurley, M.; Karande, K.; Reinartz, W.J. (1998) The impact of internal and external reference prices on brand choice: The moderating role of contextual variables. Journal of Retailing, 74 (3): 401-426

Lee, L.; Loewenstein, G.; Ariely, D.; Hong, J.; Young, J. (2008) If I'm Not Hot, Are You Hot or Not?: Physical-Attractiveness Evaluations and Dating Preferences as a Function of One's Own Attractiveness. Psychological Science, 19: 669-677.

Leibenstein, H. (1950) Bandwagon, Snob, and Veblen Effects in the Theory of Consumers' Demand. The Quarterly Journal of Economics, 64 (2): 183-207. 
Lockshin, L.; Jarvis, W.; d'Hauteville, F.; Perrouty, J.-P. (2006) Using simulations from discrete choice experiments to measure consumer sensitivity to brand, region, price, and awards in wine choice. Food Quality and Preference, 17 (3-4): 166-178.

Lowe, B.; Alpert, F. (2010) Pricing strategy and the formation and evolution of reference price perceptions in new product categories. Psychology and Marketing, 27 (9): 846-873.

Lusk, J. L. (2003) Effects of Cheap Talk on Consumer Willingness-to-Pay for Golden Rice. American Journal of Agricultural Economics, 85 (4): 840-856.

Mayhew, G. E.; Winer, R. S. (1992) An Empirical Analysis of Internal and External Reference Prices Using Scanner Data. The Journal of Consumer Research, 19 (1): 62-70.

Mazumdar, T.; Papatla, P. (2000) An Investigation of Reference Price Segments. Journal of Marketing Research, 37 (2): 246-258.

Mazumdar, T.; Raj, S.P.; Sinha, I. (2005) Reference Price Research: Review and Propositions. Journal of Marketing, 69, 84-102.

Milgrom, P.; Roberts, J. (1986) Price and Advertising Signals of Product Quality. Journal of Political Economy, 94 (4): 796-821.

Mitchell, V. W.; Greatorex, M. (1989) Risk Reducing Strategies Used in the Purchase of Wine in the UK. International Journal of Wine Business Research, 1 (2): 31-46.

Monroe, K. B. (1973) Buyers' Subjective Perceptions of Price. Journal of Marketing Research, 10 (1): 70-80.

Mueller, S.; Lockshin, L.; Louviere, J. (2010) What you see may not be what you get: Asking consumers what matters may not reflect what they choose. Marketing Letters, 21 (4): 335-350.

Palazon, M.; Delgado-Ballester, E. (2009) Effectiveness of price discounts and premium promotions. Psychology and Marketing, 26 (12): 1108-1129.

Panzone, L. (2012). Alcohol Tax, Price-Quality Proxy and Discounting: A Reason Why Alcohol Taxes May Rebound. Journal of Agricultural Economics, 63 (3). 
Park, J. H.; MacLachlan, D. L. (2008) Estimating Willingness to Pay with Exaggeration BiasCorrected Contingent Valuation Method. Marketing Science, 27: 691-698.

Peri, Claudio (2006) The universe of food quality. Food Quality and Preference, 17 (1-2): 3-8.

Plassmann, H.; O'Doherty, J.; Shiv, B.; Rangel, A. (2008) Marketing actions can modulate neural representations of experienced pleasantness. Proceedings of the National Academy of Sciences (PNAS), 105: 1050-1054.

Porath, C.; MacInnis, D.; Folkes, V. (2010) Witnessing Incivility among Employees: Effects on Consumer Anger and Negative Inferences about Companies. Journal of Consumer Research, 37 (2): 292-303.

Rao, A (2005). The Quality of Price as a Quality Cue. Journal of Marketing Research, 42 (4): 401405.

Rao, A. R.; Monroe, K. B. (1989) The Effect of Price, Brand Name, and Store Name on Buyers' Perceptions of Product Quality: An Integrative Review. Journal of Marketing Research, 26 (3): 351-357.

Ritchie, C. (2007) Beyond drinking: the role of wine in the life of the UK consumer. International Journal of Consumer Studies, 31 (5): 534-540.

Rowe, R. D.; Schulze, W. D.; Breffle, W. S. (1996) A Test for Payment Card Biases. Journal of Environmental Economics and Management, 31 (2): 178-185.

Scarpa, R.; Gilbride, T. J.; Campbell, D.; Hensher, D. A. (2009) Modelling attribute non-attendance in choice experiments for rural landscape valuation. European Review of Agricultural Economics, 36 (2): 151-174.

Schindler, R.M.; Kibarian, T.M. (1996) Increased consumer sales response through use of 99ending prices. Journal of Retailing, 72 (2): 187-199.

Schindler, R.M.; Kirby, P. N. (1997) Patterns of Rightmost Digits Used in Advertised Prices: Implications for Nine Ending Effects. Journal of Consumer Research, 24 (2): 192-201. 
Shiv, B.; Carmon, Z.; Ariely, D. (2005a) Placebo Effects of Marketing Actions: Consumers May Get What They Pay For. Journal of Marketing Research, 42: 383-393.

Shiv, B.; Carmon, Z.; Ariely, D. (2005b) Ruminating About Placebo Effects of Marketing Actions. Journal of Marketing Research, 42: 410-414.

Smith, N. K.; Larsen, J.T.; Chartrand, T.L.; Cacioppo, J.T.; Katafiasz, H.A.; Moran, K.E. (2006) Being bad isn't always good: Affective context moderates the attention bias toward negative information. Journal of Personality and Social Psychology, 90 (2): 210-220.

Spence, M. (1973) Job Market Signaling. The Quarterly Journal of Economics, 87 (3): 355-374.

Spence, M. (2002) Signaling in Retrospect and the Informational Structure of Markets. The American Economic Review, 92 (3): 434-459.

Stiglitz, J. E. (1987) The Causes and Consequences of The Dependence of Quality on Price. Journal of Economic Literature, 25 (1): 1-48.

Thaler, R. (1985) Mental Accounting and Consumer Choice. Marketing Science, 4: 199-214.

Thomas, M. (2013) Commentary on behavioral price research: the role of subjective experiences in price cognition. AMS Review, 1-5.

Thomas, M.; Morwitz, V. G.; Lodish, L. M. (2004) When Do Higher Prices Increase Demand? The Dual Role of Price in Consumers' Value Judgments. University of New York Stern School of Business working $\quad$ paper. $\quad$ Available an http://pages.stern.nyu.edu/ mkt/wps/MARK\%2001\%2004\%20Thomas\%20Morwitz\%20and \%20Lodish-1.pdf.

Tversky, A.; Kahneman, D. (1974) Judgment under uncertainty: Heuristics and biases. Science, $185,1124-1130$.

Veblen, T. (1899) The theory of the leisure class. Prometheus Books, Amherst, NY. Published in 1998.

Venkatachalam, L. (2004) The contingent valuation method: a review. Environmental Impact Assessment Review, 24 (1): 89-124. 
Wang, H. (1997) Treatment of 'Don't-Know' Responses in Contingent Valuation Surveys: A Random Valuation Model. Journal of Environmental Economics and Management, 32 (2): 219-232.

Welsh, M. P.; Poe, G. L. (1998) Elicitation Effects in Contingent Valuation: Comparisons to a Multiple Bounded Discrete Choice Approach. Journal of Environmental Economics and Management, 36 (2): 170-185.

Wertenbroch, K.; Skiera, B. (2002) Measuring Consumers' Willingness to Pay at the Point of Purchase. Journal of Marketing Research, 39 (2): 228-241.

Zeithaml, V.A. (1988) Consumer Perceptions of Price, Quality, and Value: A Means-End Model and Synthesis of Evidence. The Journal of Marketing, 52 (3): 2-22. 


\section{FIGURES}

Figure 1: Example of labels in the survey

\begin{tabular}{|c|c|}
\hline Kumala Zenith & Sainsbury's \\
\hline Chenin Blanc/Chardonnay & Grenache Rosé \\
\hline 2008 & Vin de Pays de l'Ardeche \\
\hline White wine & Rosé wine \\
\hline South Africa & France \\
\hline $12.5 \%$ alcohol & $13.5 \%$ alcohol \\
\hline Villa Pendio & Sainsbury's \\
\hline Pinot Grigio & Cabernet Sauvignon \\
\hline 2008 & 2007 \\
\hline White wine & Red wine \\
\hline Hungary & Chile (Central Valley) \\
\hline $12.5 \%$ alcohol & $14 \%$ alcohol \\
\hline First Cape Limited Release & Sainsbury's \\
\hline Merlot & White wine \\
\hline 2007 & South Africa \\
\hline Red wine & $13.5 \%$ alcohol \\
\hline South Africa & \\
\hline $13.5 \%$ alcohol & \\
\hline Villa Pendio & Hawksburn Hills \\
\hline Pinot Grigio & Pinot Noir \\
\hline 2008 & 2006 \\
\hline White wine & Red wine \\
\hline Hungary & New Zealand \\
\hline $12.5 \%$ alcohol & $13.5 \%$ alcohol \\
\hline
\end{tabular}

Figure 2: Comparison of the distribution of price variables in the sample 


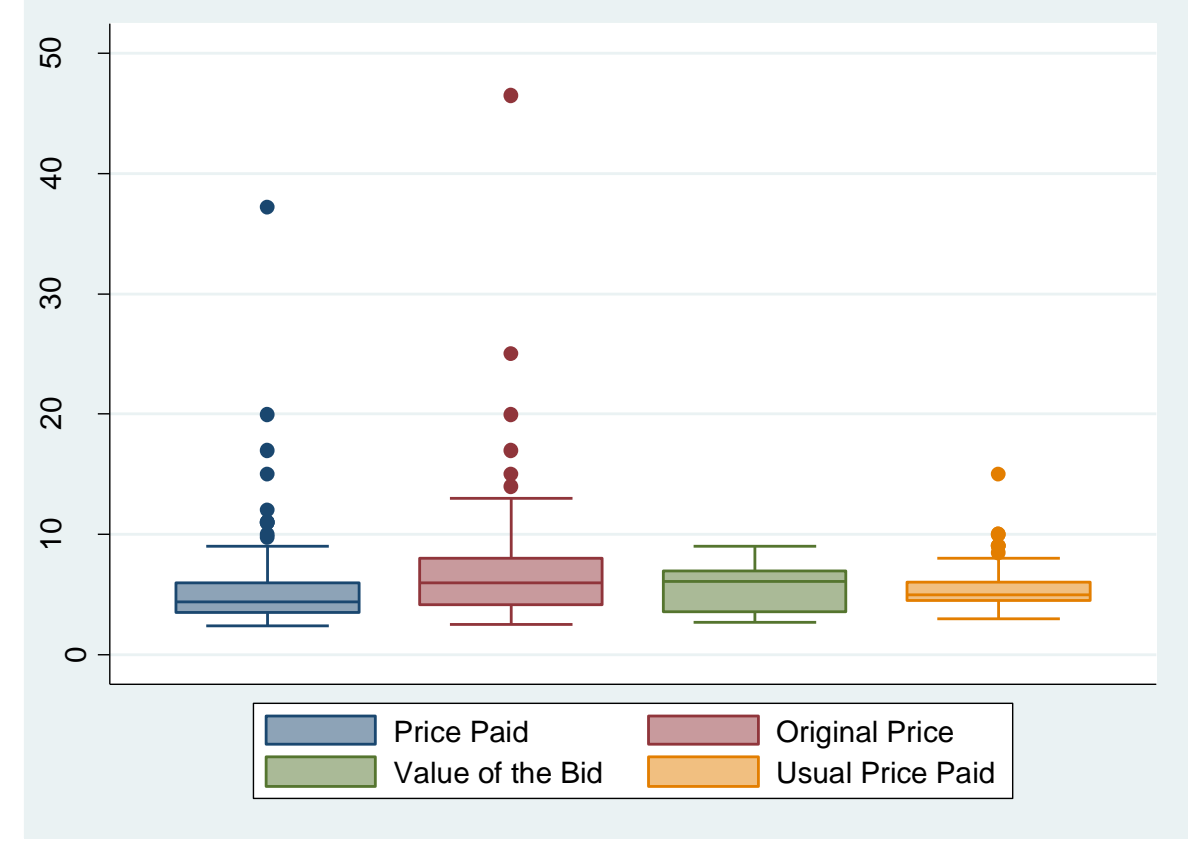

Figure 3: Trend in market price and ERP in Tesco stores by size in the study area, June 2008-May 2009

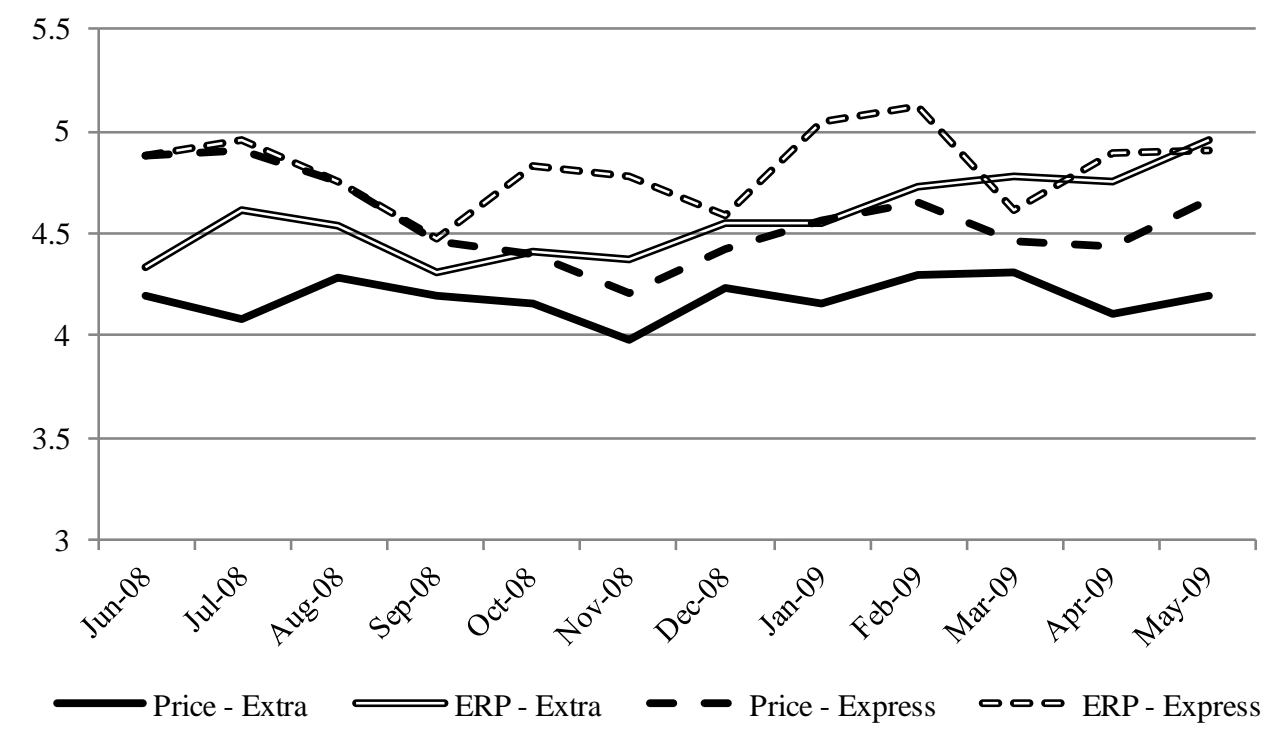

Source: courtesy of Dunnhumby Ltd

Figure 4: Graphical representation of the impact of price and ERP on utility 


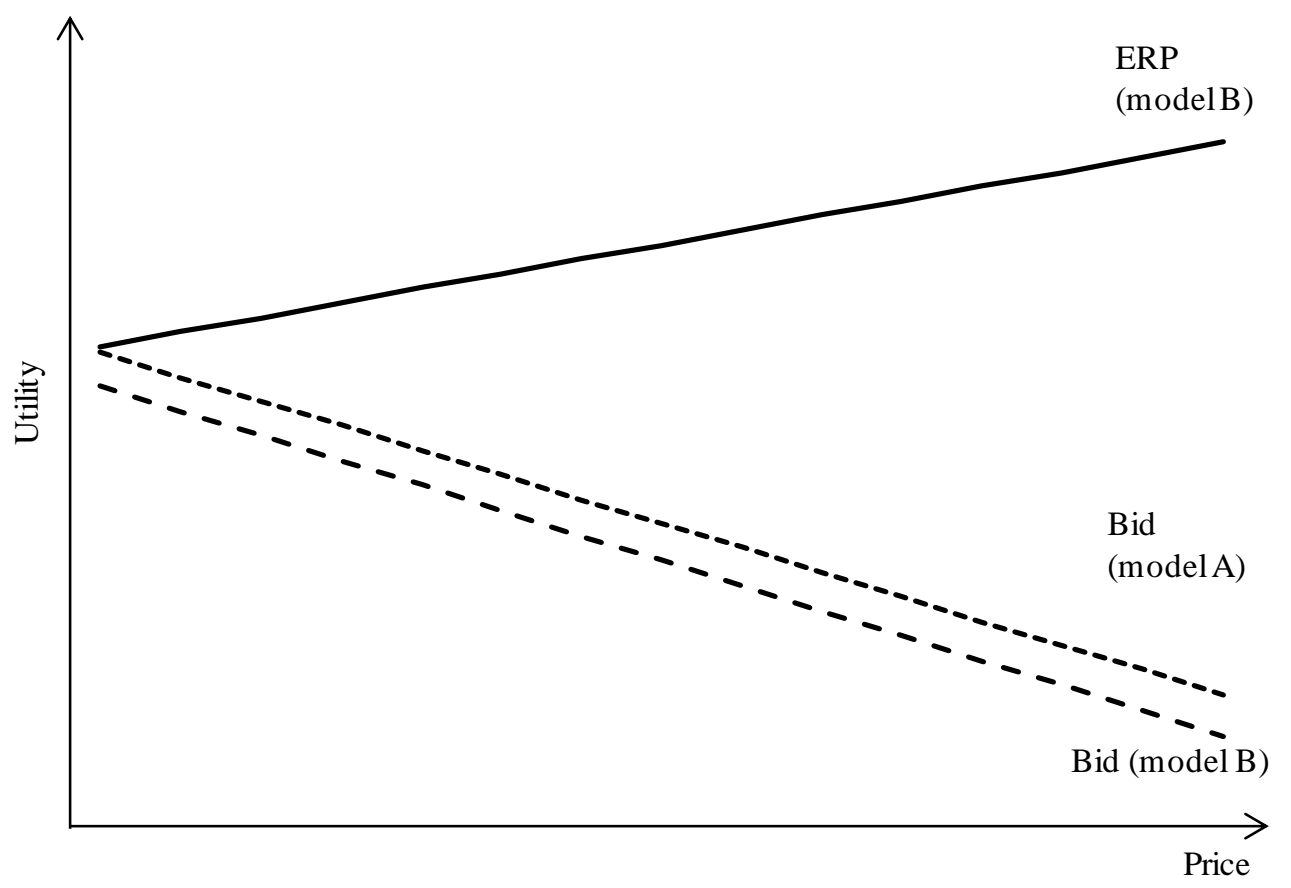

Figure 5: Graphical representation of the impact of full price of the wine on utility at changing levels of discounts

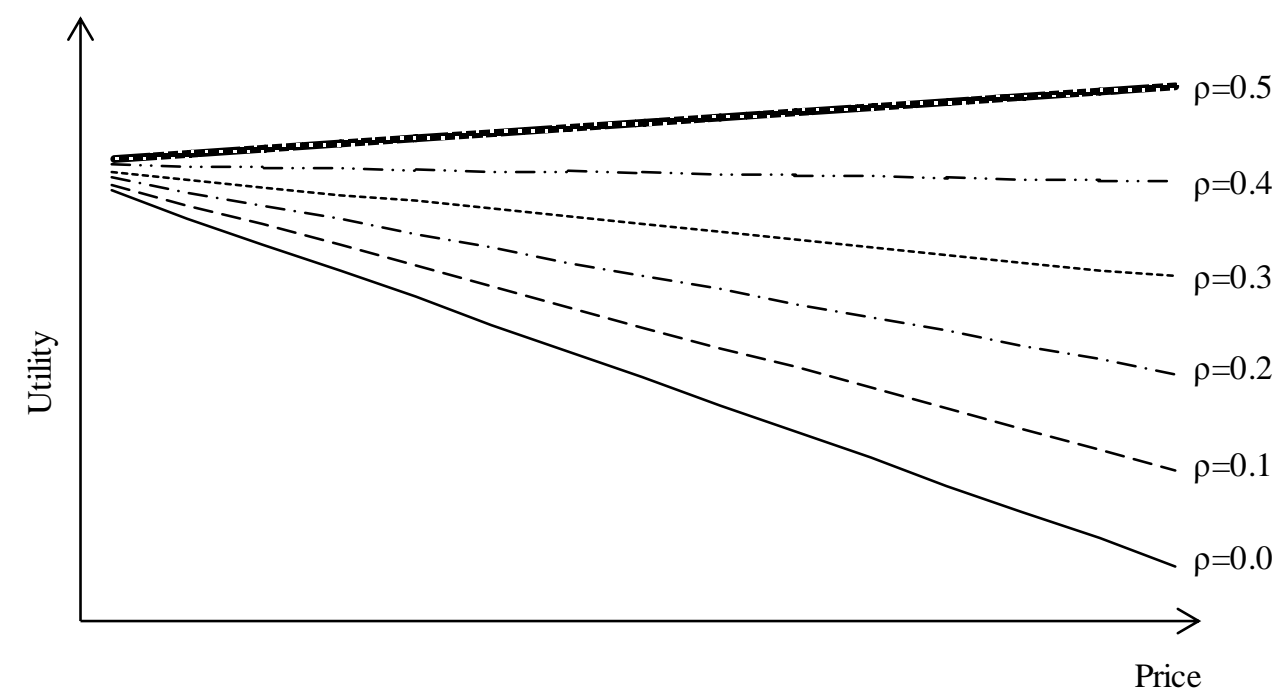

Figure 6: Scatter diagram relating the answers to the two CV surveys ( $2^{\text {nd }}$ bidding round). 


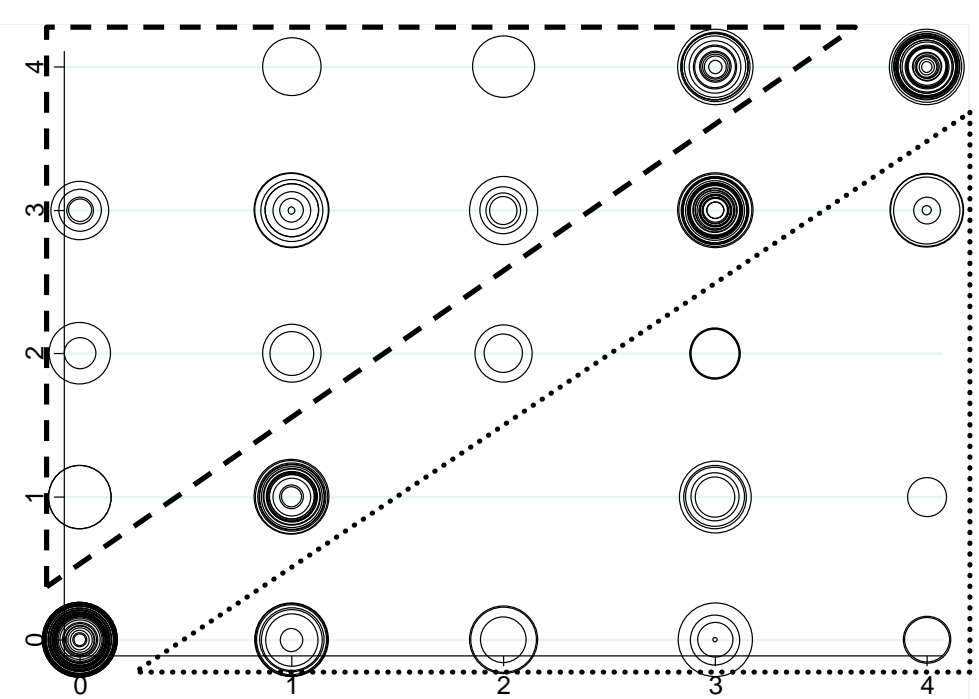

First choice - First round

Note: The dashed triangle includes respondents reporting a higher utility in their second choice compared to their first choice. The dotted triangle includes respondents doing the opposite.

\section{TABLES}

Table 1: Market share (volume) of wine sales in supermarkets in the sample and in the UK

\begin{tabular}{l|cc}
\hline & This sample & UK (2009) \\
\hline Tesco & $28.80 \%$ & $26.80 \%$ \\
Sainsbury's & $21.90 \%$ & $14.90 \%$ \\
Asda & $18 \%$ & $9.60 \%$ \\
Morrisons & $4.30 \%$ & $9.10 \%$ \\
Waitrose & $13.30 \%$ & $3.80 \%$ \\
Somerfield & $1.90 \%$ & $2.00 \%$ \\
Cooperative Group & $4.60 \%$ & $5.30 \%$ \\
Other grocery and convenience stores & $1.2 \%($ Aldi only) & $6.70 \%$ \\
\hline Total Grocery and Convenience stores & $\mathbf{9 4 \%}$ & $\mathbf{7 8 . 0 0 \%}$ \\
\hline First Quench & - & $4.60 \%$ \\
Majestic Wine Warehouse & - & $2.70 \%$ \\
Oddbins & $6 \%$ & $1.00 \%$ \\
Other specialists & - & $3.70 \%$ \\
\hline Total specialists & $\mathbf{6 \%}$ & $\mathbf{1 2 . 1 0 \%}$ \\
\hline Direct wines (Laithwaites) & - & $5.20 \%$ \\
\multicolumn{1}{c|}{ Other (including other mail order) } & - & $4.70 \%$ \\
\hline Source: UK values are from Minel, cited in & Bainbridge (2009), based
\end{tabular}

Source: UK values are from Mintel, cited in Bainbridge (2009), based on annual reports and accounts

Table 2: Value of the bids for the different version of the CV experiment

\begin{tabular}{l|cccc}
\hline & Version 1 & Version 2 & Version 3 & Version 4 \\
\hline Lower bid & 2.69 & 3.09 & 3.59 & 3.99 \\
Starting bid & 3.99 & 4.59 & 5.39 & 5.99 \\
Higher bid & 6.09 & 6.99 & 8.09 & 8.99 \\
\hline
\end{tabular}

Table 3: Summary statistics of prices of the wines in the sample 


\begin{tabular}{l|cccc}
\hline & Last bid proposed & Original price & Price usually paid & Market price \\
\hline Mean & $£ 5.44$ & $£ 6.79$ & $£ 5.41$ & $£ 5.17$ \\
Median & $£ 6.09$ & $£ 5.99$ & $£ 5.00$ & $£ 4.39$ \\
Range & $£ 2.69-£ 8.99$ & $£ 2.49-£ 46.49$ & $£ 3.00-15$ & $£ 2.37-£ 37.19$ \\
\hline
\end{tabular}

Table 4: Variables included in the estimation of the utility function.

\begin{tabular}{l|l|c|c|c}
\hline Variable & Description & Min & Max & Mean \\
\hline ERP & External reference price of the wine. & $£ 2.49$ & $£ 46.49$ & $£ 6.79$ \\
Bid & Value of the second bid offered to the respondent (the price to be paid). & & & \\
& Round 1 - No ERP & 3.59 & 5.99 & 4.97 \\
& Round 2 - No ERP & 2.69 & 8.99 & 5.50 \\
& Round 1 - With ERP & 3.59 & 5.99 & 4.99 \\
Alcohol & Round 2 - With ERP & 2.69 & 8.99 & 5.44 \\
White & Alcohol content of the wine. & 9 & 14.9 & 12.81 \\
Red & Dummy equal to one if the wine is white (baseline: rosé). & 0 & 1 & 0.37 \\
Private label & Dummy equal to one if the wine is red (baseline: rosé). & 0 & 1 & 0.55 \\
Age of wine & Dummy equal to one if the wine is branded using the retailer's name. & 0 & 1 & 0.14 \\
No year & Age of the wine (years). & 1 & 8 & 2.44 \\
AOC & Dummy equal to one if the wine does not report the vintage year. & 0 & 1 & 0.18 \\
Age & Dummy equal to one if the wine has an AOC (or equivalent) denomination. & 0 & 1 & 0.25 \\
Income & Age of the person answering the survey & 3.06 & 4.17 & 3.82 \\
No income & Yearly household income. & 2.01 & 4.09 & 3.60 \\
Hh drinkers & Dummy equal to 1 if the respondent did not report income. & 0 & 1 & 0.08 \\
Knowledge & Number of wine drinkers in the household. & 1 & 7 & 2.03 \\
& Self-reported knowledge, chosen amongst the following options: & & \\
& "No knowledge at all" & 0 & 1 & 0.13 \\
& "Low knowledge" & 0 & 1 & 0.58 \\
& "Fairly good knowledge" & 0 & 1 & 0.23 \\
& "Very good knowledge" & 0 & 1 & 0.06 \\
& "Wine expert" & 0 & 1 & 0.00 \\
\hline
\end{tabular}


Table 5: Parameter estimation of a utility function for wine ${ }^{7}$

\begin{tabular}{|c|c|c|c|c|c|c|c|c|c|c|c|c|c|}
\hline \multirow[b]{3}{*}{ With ERP } & $A$ & & \multicolumn{2}{|l|}{$B$} & \multicolumn{2}{|l|}{$C$} & \multicolumn{2}{|l|}{$D$} & \multicolumn{2}{|l|}{ E } & \multicolumn{2}{|l|}{$F$} & \multirow{3}{*}{$R P$} \\
\hline & \multicolumn{4}{|c|}{ SP - Demographics only } & \multicolumn{4}{|c|}{ SP - Demographics + product characteristics } & \multicolumn{4}{|c|}{ SP - Demographics + product characteristics + Experience } & \\
\hline & No & & Yes & & No & & Yes & & No & & Yes & & \\
\hline Bidding round & 1 & 2 & 1 & 2 & 1 & 2 & 1 & 2 & 1 & 2 & 1 & 2 & Nested logit \\
\hline Bid & $-0.3643 * * *$ & $-0.2817 * * *$ & $-0.2534 * * *$ & $-0.2883 * * *$ & $-0.3652 * * *$ & $-0.2928 * * *$ & $-0.2632 * * *$ & $-0.2733 * * *$ & $-0.3922 * * *$ & $-0.2961 * * *$ & $-0.2721 * * *$ & $-0.2759 * * *$ & $-0.3352 * * *$ \\
\hline S.E. & $(0.0754)$ & $(\mathbf{0 . 0 2 8 2})$ & $(0.0961)$ & $(0.0431)$ & $(0.0828)$ & $(\mathbf{0 . 0 3 2 5})$ & $(0.0988)$ & (0.0459) & $(0.0832)$ & $(\mathbf{0 . 0 3 1 6 )}$ & (0.1029) & $(0.0471)$ & $(-0.0754)$ \\
\hline Original price & & & $0.1584 * * *$ & $0.1679 * * *$ & & & $0.1166 * *$ & $0.1735 * * *$ & & & $0.1108 * *$ & $0.1696 * * *$ & $0.3380 * * *$ \\
\hline S.E. & & & $(0.0465)$ & $(\mathbf{0 . 0 3 5 8 )}$ & & & $(0.0522)$ & $(0.0443)$ & & & $(0.0513)$ & $(0.0448)$ & $(-0.0770)$ \\
\hline Ln (income) & -0.0258 & $-0.2547 * *$ & -0.0386 & -0.2176 & -0.0181 & $-0.2865^{* *}$ & -0.0158 & $-0.2705^{*}$ & 0.0421 & $-0.2310^{*}$ & 0.0312 & -0.2329 & \\
\hline S.E. & $(0.1224)$ & $(0.1291)$ & $(0.1432)$ & $(0.1450)$ & $(0.1296)$ & $(0.1354)$ & $(0.1460)$ & $(0.1479)$ & $(0.1289)$ & $(0.1341)$ & $(0.1481)$ & $(0.1510)$ & \\
\hline No income & -0.1761 & 0.1631 & 0.2056 & 0.3190 & -0.1199 & 0.3020 & 0.1711 & 0.3829 & -0.1058 & 0.3828 & 0.2362 & 0.4463 & \\
\hline S.E. & $(0.2891)$ & $(0.2838)$ & $(0.2773)$ & $(0.2822)$ & $(0.2874)$ & $(0.2850)$ & $(0.2950)$ & $(0.2901)$ & $(0.2918)$ & $(0.2913)$ & $(0.2978)$ & $(0.2998)$ & \\
\hline Hh drinkers & 0.0477 & 0.1346 & -0.0374 & 0.0876 & 0.0445 & 0.1587 & -0.0318 & 0.1134 & 0.0984 & $0.1911^{*}$ & -0.0051 & 0.1376 & \\
\hline S.E. & $(0.0951)$ & $(0.1081)$ & $(0.1232)$ & $(0.1047)$ & $(0.0928)$ & $(0.0997)$ & $(0.1204)$ & (0.1064) & $(0.0925)$ & $(0.0995)$ & $(0.1226)$ & $(0.1052)$ & \\
\hline Ln (age) & -0.2540 & -0.3545 & $-0.4955^{* *}$ & $-0.6089 * *$ & -0.2969 & -0.3750 & $-0.4841^{* *}$ & $-0.5823^{* *}$ & -0.2215 & -0.3450 & $-0.4681^{*}$ & $-0.5819 * *$ & \\
\hline S.E. & $(0.2219)$ & $(0.2269)$ & $(0.2394)$ & $(0.2381)$ & $(0.2260)$ & $(0.2337)$ & $(0.2444)$ & $(0.2506)$ & $(0.2263)$ & $(0.2376)$ & $(0.2522)$ & $(0.2506)$ & \\
\hline Alcohol & & & & & 0.0876 & $0.1989 * *$ & 0.0293 & 0.1117 & 0.1295 & $0.2198 * *$ & 0.0462 & 0.1218 & $0.2836 * * *$ \\
\hline S.E. & & & & & $(0.0955)$ & $(0.0981)$ & $(0.1157)$ & $(0.0960)$ & $(0.0963)$ & $(0.0988)$ & $(0.1151)$ & $(0.0985)$ & $(0.0840)$ \\
\hline White & & & & & $-0.4650 *$ & $-0.4778^{*}$ & 0.0529 & $-0.5917 * *$ & $-0.4878^{*}$ & $-0.4777 *$ & 0.0480 & $-0.5935^{* *}$ & $0.5313 * * *$ \\
\hline S.E. & & & & & $(0.2688)$ & $(0.2710)$ & $(0.3119)$ & $(0.2730)$ & $(0.2760)$ & $(0.2675)$ & $(0.3169)$ & $(0.2694)$ & $(0.0759)$ \\
\hline Red & & & & & -0.3265 & -0.5079 & 0.0685 & $-0.5565^{*}$ & -0.3713 & -0.5014 & 0.0614 & $-0.5535^{*}$ & $0.5434 * * *$ \\
\hline S.E. & & & & & $(0.3104)$ & $(0.3159)$ & $(0.3618)$ & $(0.3151)$ & $(0.3180)$ & $(0.3163)$ & $(0.3706)$ & $(0.3158)$ & $(0.0901)$ \\
\hline AOC & & & & & -0.2482 & -0.0517 & -0.0454 & -0.2273 & -0.2010 & -0.0524 & -0.0371 & -0.2275 & 0.1412 \\
\hline S.E. & & & & & $(0.2101)$ & $(0.2036)$ & $(0.1999)$ & $(0.2030)$ & $(0.2128)$ & $(0.2069)$ & $(0.2030)$ & $(0.2064)$ & $(0.2118)$ \\
\hline Private label & & & & & -0.2870 & -0.1173 & -0.0785 & -0.1242 & -0.2784 & -0.1265 & -0.0854 & -0.1347 & $1.6241 * * *$ \\
\hline
\end{tabular}

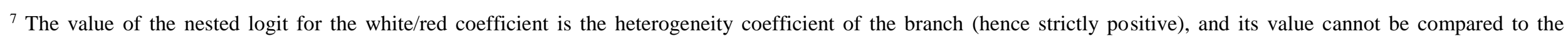
coefficient of white wines in the ordered probit. 


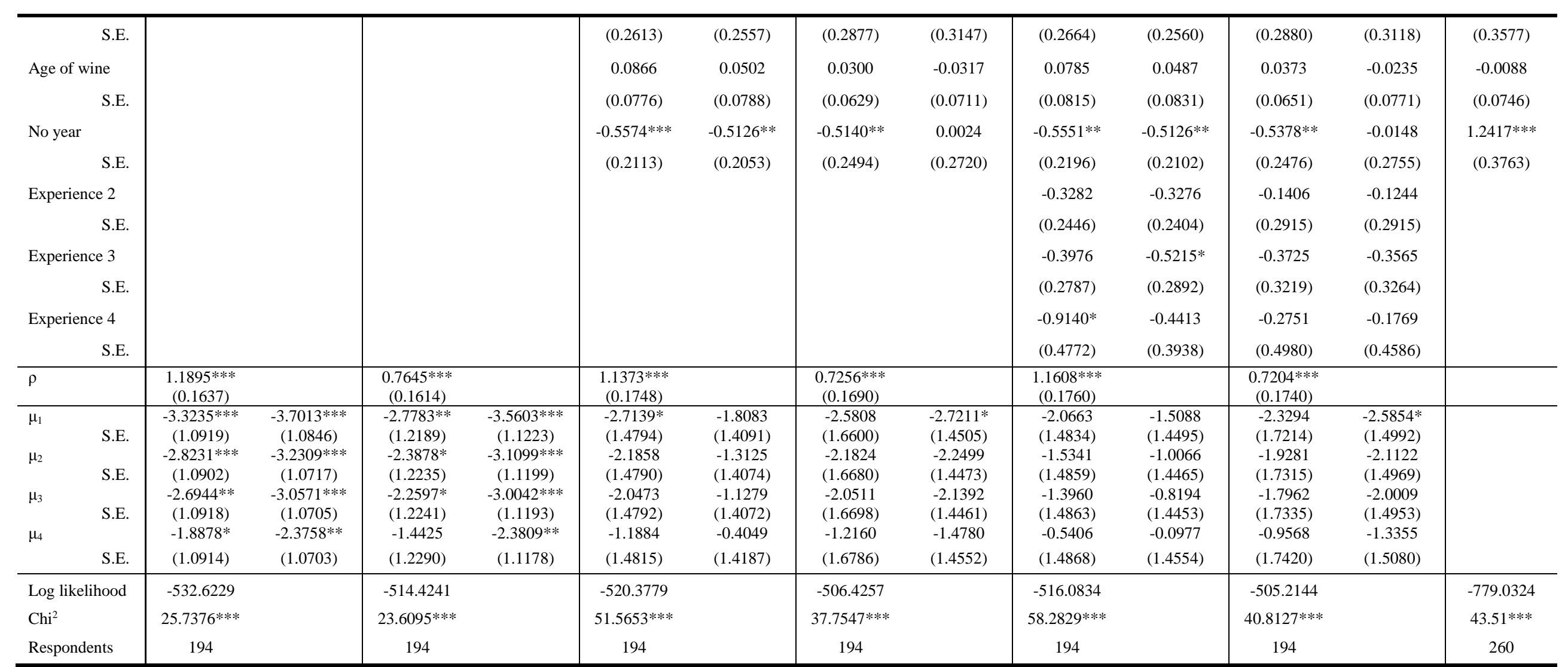

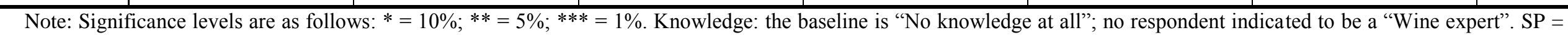
Stated Preferences; RP = Revealed Preferences. 
Table 6: Wald tests of equality of coefficients

\begin{tabular}{|c|c|c|c|c|c|c|c|}
\hline & $\boldsymbol{H}_{0}$ & $\boldsymbol{A}$ & $\boldsymbol{B}$ & $\boldsymbol{C}$ & $\boldsymbol{D}$ & $\boldsymbol{E}$ & $\boldsymbol{F}$ \\
\hline Bid $($ round 1$)=\operatorname{Bid}($ round 2$)$ & \multirow{2}{*}{$\begin{array}{c}\alpha_{3}, \beta_{3}=\mathrm{k} \\
\alpha_{4}=\mathrm{k}\end{array}$} & \multirow[t]{2}{*}{1.56} & 0.17 & \multirow[t]{2}{*}{1.01} & 0.01 & \multirow[t]{2}{*}{1.74} & 0.00 \\
\hline $\mathrm{ERP}($ round 1$)=\mathrm{ERP}($ round 2$)$ & & & 0.06 & & 1.60 & & 1.80 \\
\hline $\mathrm{Bid}+\mathrm{ERP}($ round 1$)=0$ & \multirow[t]{2}{*}{$\alpha_{3}+\alpha_{4}=0$} & & 0.77 & & 1.68 & & 1.95 \\
\hline $\mathrm{Bid}+\mathrm{ERP}($ round 2$)=0$ & & & $7.95 * * *$ & & $3.13 *$ & & $3.39 *$ \\
\hline $\begin{array}{r}\mathrm{Bid}+\mathrm{ERP} \mathrm{B} / \mathrm{D} / \mathrm{F}(\text { round } 1)= \\
\mathrm{Bid} \mathrm{A} / \mathrm{C} / \mathrm{E}(\text { round } 1)\end{array}$ & \multirow[t]{2}{*}{$\alpha_{3}+\alpha_{4}=\beta_{3}$} & & $6.21 * *$ & & $3.73 *$ & & $3.99 * *$ \\
\hline $\begin{array}{r}\mathrm{Bid}+\mathrm{ERP} \mathrm{B} / \mathrm{D} / \mathrm{F}(\text { round } 2)= \\
\mathrm{Bid} \mathrm{A} / \mathrm{C} / \mathrm{E}(\text { round } 2)\end{array}$ & & & $14.27 * * *$ & & $11.70 * * *$ & & $10.81 * * *$ \\
\hline $\mathrm{Bid} \mathrm{B} / \mathrm{D} / \mathrm{F}($ round 1$)=\mathrm{Bid} \mathrm{A} / \mathrm{C} / \mathrm{E}($ round 1$)$ & \multirow[t]{2}{*}{$\alpha_{3}=\beta_{3}$} & & 1.33 & & 1.06 & & 1.36 \\
\hline $\mathrm{Bid} \mathrm{B} / \mathrm{D} / \mathrm{F}($ round 2$)=\mathrm{Bid} \mathrm{A} / \mathrm{C} / \mathrm{E}($ round 2$)$ & & & 0.02 & & 0.18 & & 0.18 \\
\hline
\end{tabular}

Note: Significance levels are specified as follows: $*=10 \% ; * *=5 \%$; $* *=1 \%$. All tests have one degree of freedom.

Table 7: Relative importance of the ERP and IRP in the choice of wine

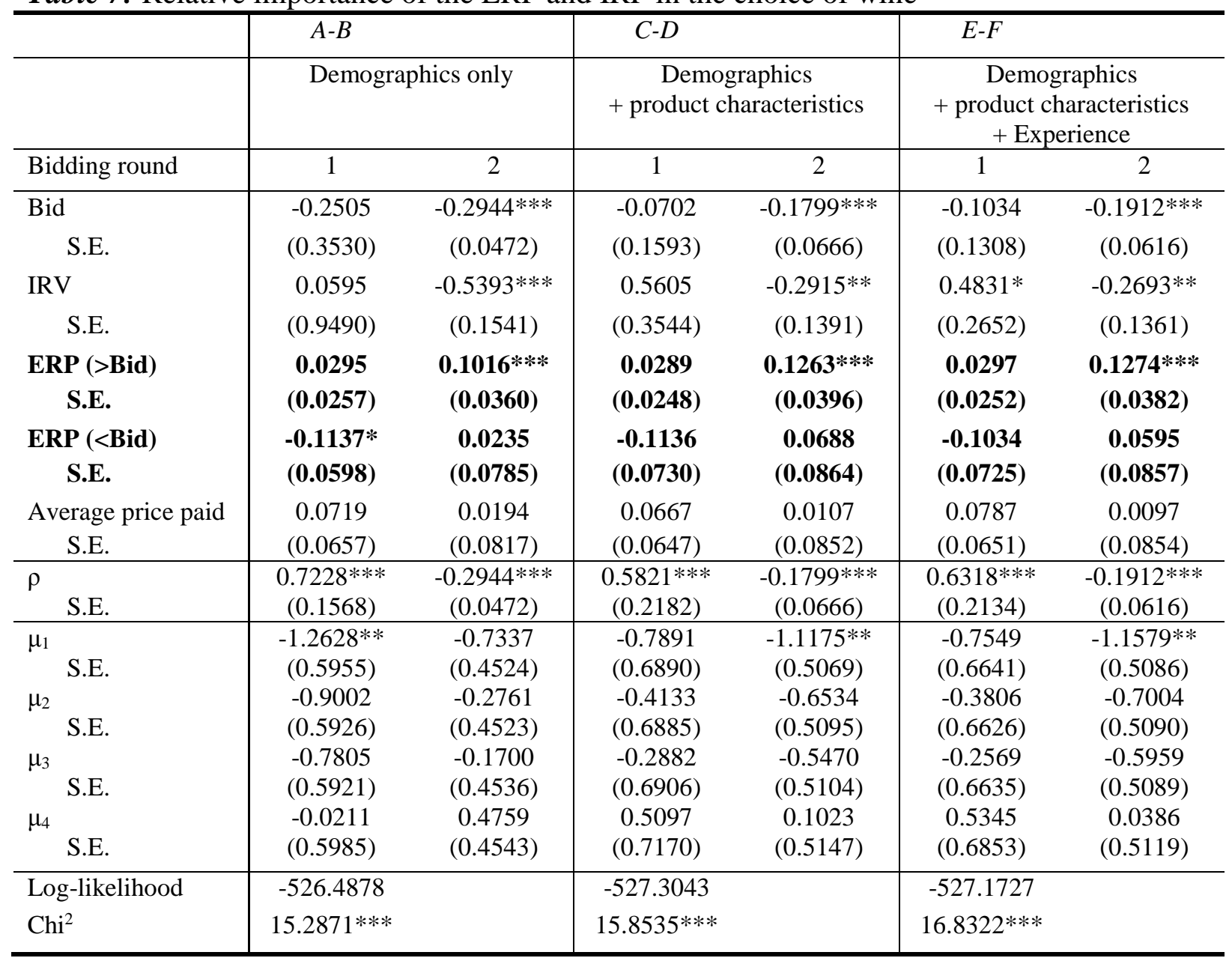

$\mathrm{N}=194$. Note: Significance levels are specified as follows: $*=10 \% ; * *=5 \% ; * * *=1 \%$.

Table 8: Conditional log-odds ratios of revising utility and the relative position of the ERP

\begin{tabular}{l|cl}
\hline & $E R P>B i d$ & $E R P<B i d$ \\
\hline Revised up & $6.4444 * * *$ & $0.1648 * * *$ \\
Revised down & $0.1552 * * *$ & $6.0677 * * *$ \\
\hline
\end{tabular}

Adjusted by self-reported knowledge and purchase rate. Observations $=69$ (respondents who changed in the first choice across survey). 